\title{
Testing a continuous measure of recreation specialization among birdwatchers
}

\author{
H. W. Harshaw (D) ${ }^{a}$, Nicholas W. Cole ${ }^{b}$, Ashley A. Dayer (D) ${ }^{c}$, Jonathan D. Rutter (D) ${ }^{c}$, \\ David C. Fulton ${ }^{d}$, Andrew H. Raedeke ${ }^{\mathrm{e}}{ }^{\mathrm{e}}$, Rudy M. Schuster ${ }^{\mathrm{b}}$, and Jennifer N. Duberstein \\ ${ }^{\mathrm{a}}$ Faculty of Kinesiology Sport, and Recreation, University of Alberta, Edmonton, Alberta, Canada; ${ }^{b}$ Fort Collins \\ Science Center, United States Geological Survey, Fort Collins, Colorado, USA; 'Department of Fish and Wildlife \\ Conservation, Virginia Polytechnic Institute and State University, Blacksburg, Virginia, USA; dUnited States \\ Geological Survey, Minnesota Cooperative Fish and Wildlife Research Unit, University of Minnesota, St. Paul,

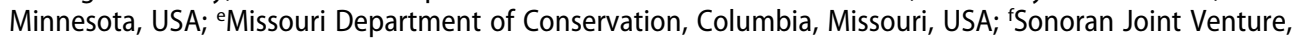 \\ United States Fish and Wildlife Service, Tucson, Arizona, USA
}

\begin{abstract}
Recreation specialization is a framework that can be used to explain the variation among outdoor recreationists' preferences, attitudes, and behaviors. Recreation specialization has been operationalized using several approaches, including summative indices, cluster analysis, and self-classification categorical measures. Although these approaches measure the multiple dimensions of the framework, they may not reflect the relative contribution of the dimensions to individuals' degree of engagement. We illustrate an approach that uses secondorder confirmatory factor analysis (CFA) factor scores as weights to determine a person's degree of recreation specialization and compares the CFA-based results to those derived from cluster analysis. This approach permits the use of a broader set of statistical tests when compared to categorical specialization measures and provides information about the distribution of responses. Data were collected from an online survey of eBird registrants from the United States.
\end{abstract}

\section{KEYWORDS}

Recreation specialization; birdwatching; second-order confirmatory factor analysis; cluster analysis

\section{Introduction}

Recreation specialization provides a theoretical framework to help understand how individuals' participation in a specific outdoor recreation activity may move along a continuum from general involvement to deeper levels of involvement. It represents a dynamic process whereby recreationists transition from one developmental stage to another as skills, attitudes, desired experience, and even external constraints change. Recreationists with higher degrees of specialization can have different motives for participating in an activity, tend to focus on the quality of the recreation experience, and place more importance on nonactivity specific elements like the setting. Specialists' perceptions of crowding, equipment, and centrality to lifestyle also differ from generalists' perceptions (Salz et al., 2001). As specialization increases, so does commitment to the recreation activity, such that it can become a person's life focus, and may become a central, dominant force that serves as a standard of reference (Scott \& Shafer, 2001). 
The recreation specialization framework was originally conceptualized as the degree of behavioral involvement in an outdoor recreation activity (Bryan, 1977). It has since been evaluated and redeveloped into a multidimensional construct (Scott \& Shafer, 2001). The framework is composed of three interrelated and mutually reinforcing dimensions: affective, behavioral, and cognitive (McIntyre \& Pigram, 1992). The affective dimension incorporates the psychological attachment that recreationists develop to particular outdoor recreation activities and is expressed in terms of the importance of an activity, the enjoyment derived from an activity, self-expression through an activity, and the degree of centrality that an activity assumes in a person's life. As recreation specialization increases, it is expected that measures of enduring involvement will increase. The behavioral dimension incorporates the frequency of participation, prior experience, and the recreationist's familiarity with particular settings: as recreation specialization increases, so does the frequency of participation, and familiarity with particular settings. The cognitive dimension incorporates the knowledge and skills that a recreationist acquires over time; both knowledge and skills increase and become more focused as specialization increases (McIntyre \& Pigram, 1992).

The operationalization of recreation specialization has included approaches that have used summative indices (e.g., Salz \& Loomis, 2005; Shipley et al., 2018), cluster analysis of variables (e.g., Hvenegaard, 2002; Oh \& Ditton, 2006), cluster analysis of exploratory factor analysis scores (e.g., Lessard et al., 2017), and self-classification categorical measures (e.g., Beardmore et al., 2013; Needham et al., 2009; Scott et al., 2005). Although these approaches incorporate variables that measure the multiple dimensions of recreation specialization, they have not reflected the relative contribution of the dimensions to individuals' degree of engagement in specific outdoor recreation activities. These approaches assume that each dimension makes equal contributions to an individual's degree of specialization, which is not always the case. Although recreation specialization dimensions can be moderately related, they may not be mutually reinforcing; it is unlikely that individuals' progression in these different dimensions is uniform as the dimensions may not covary (Lee \& Scott, 2004). Given the continued recognition of the multidimensional construct approach, there is a need for a measure of recreation specialization that reflects the influence of the different dimensions of the framework by accounting for individual variation among the dimensions (Lee \& Scott, 2004). We illustrate and test an approach that uses second-order confirmatory factor analysis (CFA) factor scores as weights to determine a person's degree of recreation specialization in birdwatching based on the relative contributions of the specialization dimensions and the variables that measure these latent dimensions. This approach provides an interval measure of a person's degree of recreation specialization that allows for a broader range of multivariate statistical tests. We compare the results of this continuous measure to those derived from K-means cluster analysis.

\section{Methods}

We conducted a nationwide survey of United States (U.S.)e Bird registrants between November 16, 2016, and January 6, 2017. eBird is a citizen science project that focuses on birds and relies on birdwatchers to submit their observations. It provides resources to support birdwatchers, such as identification tips and real-time maps of species locations. eBird participants can maintain lists of their sightings and share these lists with other eBird 
participants (Sullivan et al., 2017, 2009). The sample frame was U.S. residents, aged 18 and older, with a valid e-mail address and at least one eBird login since January 1, 2012. Of the 134,111 e-mail invitations that were sent to eBird registrants, 126,083 had valid e-mail addresses. A total of 30,163 surveys had complete responses for the recreation specialization variables and were retained (24\% response rate). Drawing on established literature about recreation specialization and enduring involvement in outdoor recreation to guide development of the recreation specialization questions (e.g., Beardmore et al., 2013; Havitz \& Dimanche, 1997; Kyle et al., 2007; Lee \& Scott, 2004; McFarlane, 1994; Needham et al., 2009, Schroeder et al., 2013), we posed several questions to measure respondents' degree of recreation specialization.

We used 10 questions to measure the three dimensions of recreation specialization (Table 1). We used four items to measure the affective dimension, including one item to measure the attraction of bird watching and three items to measure how central bird watching is to people's lives (i.e., centrality). These items were similar to those used in previous studies to assess enduring leisure involvement (Beardmore et al., 2013; Jun et al., 2015, 2012; Kyle et al., 2007). Respondents indicated their level of agreement with each item on a 5 -point scale (1-strongly disagree to 5 -strongly agree).

We used three items to measure the behavioral dimension. We measured frequency of participation by combining responses from two questions: "In the past 12 months, did you take any trips at least 1 mile or more from your home primarily for bird watching" (Q4) and "In the past 12 months about how many trips at least 1 mile from your home did you take primarily for birdwatching" (Q5); this approach is consistent with previous measures of frequency of participation in a specialization context (e.g., Lee \& Scott, 2004; McFarlane, 2004; Oh et al., 2013). If respondents indicated that they had not taken any birdwatching trips in Q4 and they did not provide a response to $\mathrm{Q} 5$, we calculated frequency of participation as "0." If a response was provided for Q5, then that value was used for frequency of participation. If respondents indicated that they had taken at least one birdwatching trip in Q4 but did not provide a response to Q5, then frequency of participation was coded as "missing." We standardized frequency of participation using $\mathrm{z}$-scores so that the recoded frequency of participation variable had a mean of 0 and a standard deviation of 1 . We created a summative

Table 1. Questions used to measure eBird participants' degree of recreation specialization.

\begin{tabular}{|c|c|c|c|c|}
\hline Dimension & Variables & Question text & Mean & $S D$ \\
\hline \multirow{4}{*}{$\begin{array}{l}\text { Affective } \\
\text { dimension }\end{array}$} & Attraction & Birdwatching is one of the most enjoyable activities I do. & 4.21 & 0.811 \\
\hline & Centrality_1 & Birdwatching has a central role in my life. & 3.51 & 1.090 \\
\hline & Centrality_2 & A lot of my life is organized around birdwatching. & 2.96 & 1.132 \\
\hline & Centrality_3 & If I couldn't go birdwatching I am not sure what I would do instead. & 2.46 & 1.068 \\
\hline \multirow[t]{3}{*}{$\begin{array}{l}\text { Behavioral } \\
\text { dimension }\end{array}$} & $\begin{array}{l}\text { Frequency of } \\
\text { participation }\end{array}$ & $\begin{array}{l}\text { In the past } 12 \text { months, about how many trips at least } 1.6 \mathrm{~km} \text { ( } 1 \text { mile) from } \\
\text { your home did you take primarily for birdwatching? [This variable was } \\
\text { standardized.] }\end{array}$ & 0.00 & 1.000 \\
\hline & Equipment & $\begin{array}{l}\text { Do you have any of the following equipment that you own primarily for } \\
\text { birdwatching? [3 items: Binoculars, cameras, spotting scopes] } \\
\text { Summative variable created. }\end{array}$ & 1.80 & 0.858 \\
\hline & No equipment & I tend to just watch birds without using any special equipment. & 2.88 & 1.176 \\
\hline \multirow[t]{3}{*}{$\begin{array}{l}\text { Cognitive } \\
\text { dimension }\end{array}$} & $\begin{array}{l}\text { Expertise (self- } \\
\text { rated) }\end{array}$ & $\begin{array}{l}\text { How would you rate your own ability to observe and identify birds? } \\
\text { (7-point Scale: Novice [1] - Expert [7]) }\end{array}$ & 4.45 & 1.321 \\
\hline & Visual skill & I can identify most birds I see in the field. & 3.78 & 0.876 \\
\hline & Aural skill & I can readily identify many birds in the field by sound. & 3.12 & 1.152 \\
\hline
\end{tabular}


variable, Equipment, to measure the amount of equipment that respondents had primarily for birdwatching: one point was given for each category of equipment owned (binoculars, cameras, spotting scopes), up to a maximum value of three. Other items asked whether respondents tended to just watch birds without using any special equipment; respondents could answer on a 5-point interval agreement scale. This item was reverse coded; strong disagreement (i.e., special equipment was used) was scored as 5 and strong agreement (i.e., special equipment was not used) was scored as 1 .

We used three items to measure the cognitive dimension. The first item asked respondents to rate their self-perceived level of expertise to observe and identify birds from $1=$ novice to 7 = expert. We also asked respondents to indicate how much they disagreed or agreed (1-strong disagree to 5-strongly agree) with two statements: "I can identify most birds I see in the field," and "I can readily identify many birds in the field by sound."

\section{Data Analysis}

We conducted second-order confirmatory factor analysis (CFA) to assess the construct validity of the variables measuring the latent factors of specialization with no error covariance specified for the model. We used SPSS AMOS 26.0 for the CFA and used maximum likelihood to estimate parameters. Due to the large sample size, we employed bootstrapping with 2,000 samples specified (Wright et al., 2011). Many CFA model fit statistics are sensitive to sample size; for example, the $\chi^{2}$ statistic is often significant in large samples (Bentler \& Bonnett, 1980; Sun, 2005). Four model fit indices that are robust to large samples (Hu \& Bentler, 1999; Sun, 2005) were employed: comparative fit index (CFI); root mean squared error of approximation (RMSEA); the Tucker-Lewis index (TLI); and standardized root mean square residual (SRMR). CFI and TLI of close to or greater than .90 are recommended for acceptable model fit. Similarly, RMSEA and SRMR values <.08 suggest acceptable model (Hu \& Bentler, 1999). We employed Cronbach's Alpha to measure the internal consistency reliability of the dimensions. Kline (2011) suggests that alpha coefficients of .90 are excellent, .80 are very good, and .70 are adequate.

\section{Results}

We specified, tested, and compared four different competing models. The model that included all three recreation specialization dimensions performed the best based on item factor loadings, model fit indices, and parsimony (Figure 1). The CFA results generally suggested a good fit $\left(\chi^{2}=2744.30, d f=32, p<.001\right.$; CFI $=.975$; RMSEA = .053; TLI = .965; SRMR $=.027)$, indicating acceptable construct validity. First-order factor loadings ranged from .582 to .851 for the affective dimension (i.e., centrality), from .522 to .688 for the behavioral dimension (i.e., frequency of participation, equipment), and from .677 to .840 for the cognitive dimension (i.e., skill). The behavioral dimension (.878) represented specialization best compared to the affective (.815) and cognitive (.733) dimensions. All factor loadings were significant at $p<.001$. We used Cronbach's alpha to assess internal reliability of the three recreation specialization dimensions. The reliability score for the affective dimension was acceptable $(\alpha=.824)$. The reliability score for the behavioral dimension 


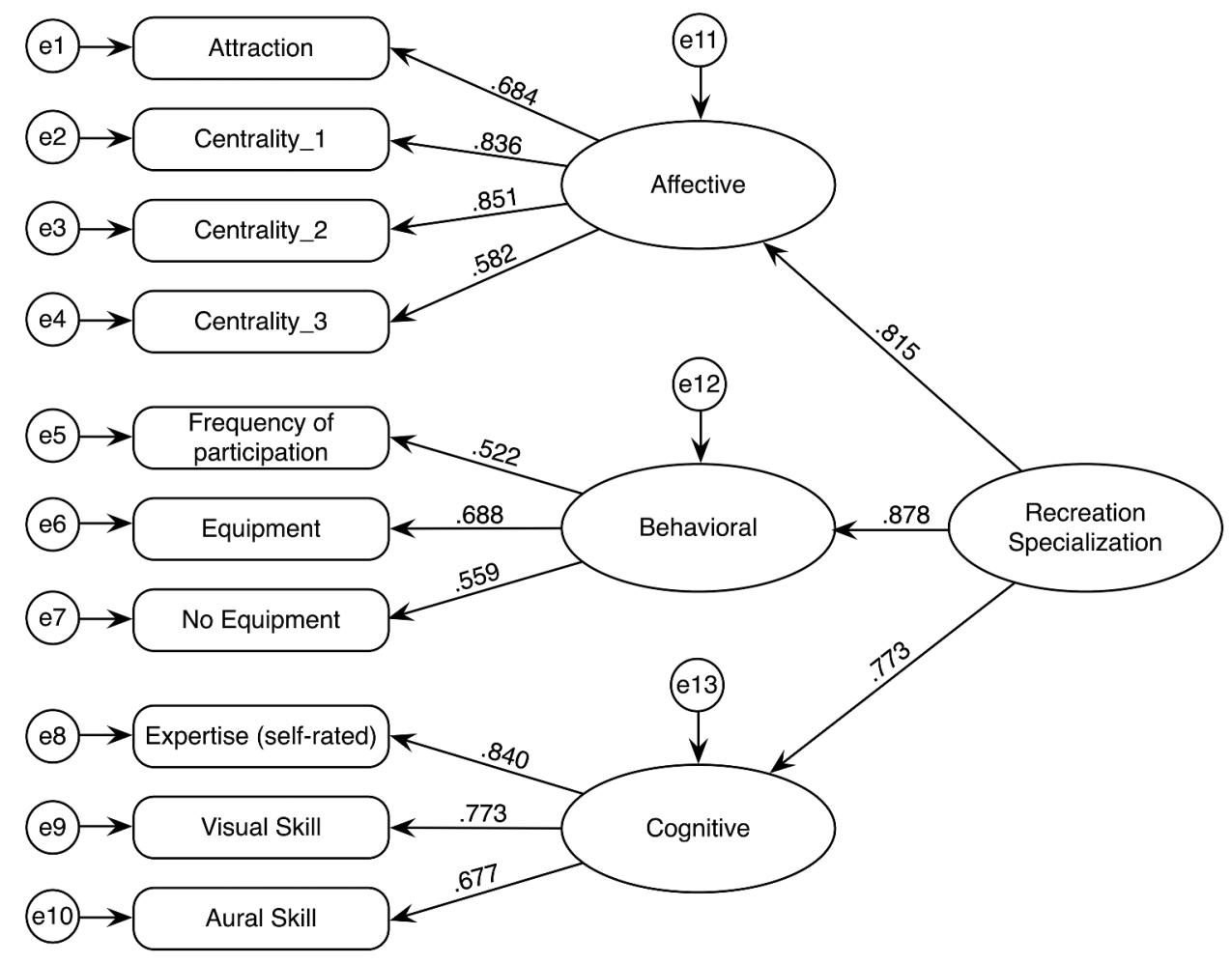

Figure 1. Confirmatory factory analysis recreation specialization model.

was poor $(\alpha=.600)$. The reliability score for the cognitive dimension was acceptable $(\alpha=.792)$. Eliminating items from each of the three dimensions did not result in any gains in reliability. The variables that were included in this model were used to operationalize recreation specialization among birdwatchers. We used the factor loadings as weights in the calculation of weighted sum scores for each respondent (i.e., a continuous measure of recreation specialization).

We employed K-means cluster analysis to differentiate levels of recreation specialization among respondents (Oh \& Ditton, 2006) using 30,163 cases. Bonferroni multiple comparison tests were run on 2, 3, 4, and 5 cluster solutions. Every pair-wise comparison of the 3 -cluster specialization variables was significantly different $(p<.001)$, which suggests that the 3-cluster solutions were stable. The other four cluster solutions were not stable, as several specialization variables were not significantly different in the pair-wise comparisons. The 3-cluster solution (Table 2) converged after 46 iterations; the minimum distance between initial cluster centers was 11.236.

We used the first- and second-order coefficients from the CFA model to create weighted sum scores (DiStefano et al., 2009) of recreation specialization. ${ }^{1}$ Descriptive statistics for the resultant continuous recreation specialization measure and the individual dimensions are presented in Table 3.

We used ANOVA to examine whether the continuous recreation variable was consistent with the 3-cluster solution (Table 4); we used $\eta^{2}$ to calculate effect size. The mean 
Table 2. 3-cluster solution: mean values for recreation specialization variables.

\begin{tabular}{lcccc}
\hline Dimension & Variables & $\begin{array}{c}\text { Cluster 1, } \\
\text { Generalist } \\
(n=8,123)\end{array}$ & $\begin{array}{c}\text { Cluster 3, } \\
\text { Intermediate } \\
(n=13,607)\end{array}$ & $\begin{array}{r}\text { Cluster 2, } \\
\text { Specialist } \\
(n=8,433)\end{array}$ \\
\hline Affective & Attraction & 3.56 & 4.23 & 4.81 \\
& Centrality_1 & 2.47 & 3.50 & 4.53 \\
Centrality_2 & 1.95 & 2.81 & 4.18 \\
Behavioral & Centrality_3 & 1.82 & 2.34 & 3.26 \\
& Frequency of participation & -0.399 & -0.245 & 0.777 \\
Cognitive & Equipment & 1.17 & 1.79 & 2.43 \\
& No equipment & 2.37 & 3.10 & 3.87 \\
& Expertise & 3.02 & 4.65 & 5.52 \\
& Visual skill & 3.00 & 3.87 & 4.40 \\
\hline
\end{tabular}

Table 3. Descriptive statistics for the recreation specialization dimension scores and for the recreation specialization continuous variable.

\begin{tabular}{lcccccccc}
\hline $\begin{array}{l}\text { Recreation specialization } \\
\text { measure }\end{array}$ & $n$ & Min. & Max. & Mean & SD & SE & Median & Mode \\
\hline Affective dimension & 30,163 & 2.41 & 12.03 & 7.96 & 2.053 & 0.012 & 7.98 & 6.61 \\
Behavioral dimension & 30,163 & 0.27 & 7.29 & 2.62 & 1.170 & 0.007 & 2.51 & 1.36 \\
Cognitive dimension & 30,163 & 1.68 & 9.62 & 6.43 & 1.607 & 0.009 & 6.71 & 7.33 \\
Recreation specialization (continuous measurement) & 30,163 & 4.35 & 28.95 & 17.01 & 3.948 & 0.023 & 17.02 & 13.70 \\
\hline
\end{tabular}

Table 4. Continuous recreation specialization descriptive statistics arranged by the 3-clusters $(n=30,163)$.

\begin{tabular}{lcccccc}
\hline & \multicolumn{5}{c}{ Continuous recreation specialization measure } \\
\cline { 2 - 7 } Specialization cluster & $n$ & Min. & Max & Mean & SD & SE \\
\hline Generalist & 8,123 & 4.35 & 17.26 & 12.19 & 1.931 & 0.021 \\
Intermediate & 13,607 & 12.36 & 20.22 & 16.92 & 1.465 & 0.013 \\
Specialist & 8,433 & 18.33 & 28.95 & 21.79 & 1.859 & 0.020 \\
\hline
\end{tabular}

continuous specialization scores for the three clusters were significantly different and had a large effect size $\left(\mathrm{F}(2,30160)=64937.19, p<.001, \eta^{2}=.812\right)$.

\section{Discussion and Conclusion}

We used confirmatory factor analysis to operationalize recreation specialization as an ordinal and interval latent variable to better represent and characterize it as a multidimensional construct. We tested whether the three specialization dimensions were present among birdwatchers and identified the variables that contributed to those three dimensions. The second-order CFA identified a good-fitting model of recreation specialization with affective, behavioral, and cognitive dimensions that were consistent with previous studies that have used the recreation specialization framework. This interval measure and comparisons with cluster analysis results support the multidimensionality of the recreation specialization framework and provide a means of measuring and understanding the relative influence of the different underlying dimensions. The interval measure results suggest that a person's degree of specialization can be developed through different paths and strengths in the different dimensions. This new approach reflects the influence of 
the different dimensions of recreation specialization and accounts for individual variation among the dimensions. This interval measure allows for the use of a broader set of statistical approaches when compared to a categorical approach and provides much more detailed information about the distribution of responses (e.g., modality, skewness, and variance). Clustering approaches are useful because they reduce complex data to a limited set of categories, determined by minimized variance within each category, and display data within an easily digestible form. Yet, within a multidimensional recreation specialization framework, we show that a continuous distribution approach may be more appropriate because it provides a more precise description of how each dimension is represented by the underlying measures of specialization within a population. It is this increased precision that broadens its application within statistical models and how outdoor recreation managers may use the results within a decision-making process.

It is possible that casual birdwatchers are under-represented in this study. However, we are not attempting to characterize the range of recreation specialization among U.S. birdwatchers, nor generalizing to this community. Instead, we have presented a method of measuring the degree of recreation specialization among participants of an outdoor recreation activity. This approach can be applied to participants of other outdoor recreation activities; however, the selection and wording of questions would differ and reflect the different activity context.

\section{Note}

1. Recreation specialization $=(0.815 \times((0.684 \times$ Attraction $)+(0.836 \times$ Centrality_1 $)+(0.851$ $\times$ Centrality_ 2$)+(0.582 \times$ Centrality_3 $)))+(0.878 \times((0.522 \times$ frequency of participation $)+$ $(0.688 \times$ Equipment $)+(0.559 \times$ No Equipment $)))+(0.733 \times((0.840 \times$ Expertise $)+(0.773$ $\times$ Visual Skill $)+(0.677 \times$ Aural Skill $)))$.

\section{Acknowledgments}

The authors wish to acknowledge the National Flyway Council and its member states, the US Geological Survey, the Migratory Bird Joint Ventures, the US Fish and Wildlife Service, Ducks Unlimited, the Association of Fish and Wildlife Agencies, the North American Bird Conservation Initiative, the Cornell Lab of Ornithology, and all members of the North American Waterfowl Management Plan Human Dimensions Working Group and Public Engagement Team for their contributions to the survey we used for this study. We also acknowledge all survey participants, whose responses were the foundation of our analysis. Finally, we acknowledge Dr. Christopher Chizinski for reviewing our manuscript prior to submission.

This draft manuscript is distributed solely for purposes of scientific peer review. Its content is deliberative and predecisional, so it must not be disclosed or released by reviewers. Because the manuscript has not yet been approved for publication by the U.S. Geological Survey (USGS), it does not represent any official USGS finding or policy. Any use of trade, firm, or product names is for descriptive purposes only and does not imply endorsement by the U.S. Government.

\section{Funding}

Funding for this project was provided by the National Flyway Council (https://www.fws.gov/birds/ management/flyways.php) through a grant to the University of Minnesota Award: CON000000054673 Project\#: 00049956 (DCF). Representatives of the National Flyway Council 
who are not named authors contributed to study design, but not to data collection/analysis, decision to publish, nor preparation of the manuscript. The preparation of this manuscript was supported by funding from the Social Sciences \& Humanities Research Council of Canada (File \# 435-2017-1352; $\mathrm{HWH})$.

\section{ORCID}

H. W. Harshaw (D) http://orcid.org/0000-0001-9568-772X

Ashley A. Dayer (D) http://orcid.org/0000-0002-8105-0776

Jonathan D. Rutter (D) http://orcid.org/0000-0001-5625-3240

Andrew H. Raedeke (D) http://orcid.org/0000-0003-3216-6868

Jennifer N. Duberstein (D) http://orcid.org/0000-0003-2974-8381

\section{References}

Beardmore, B., Haider, W., Hunt, L. M., \& Arlinghaus, R. (2013). Evaluating the ability of specialization indicators to explain fishing preferences. Leisure Sciences, 35(3), 273-292. https://doi.org/10. 1080/01490400.2013.780539

Bentler, P. M., \& Bonnett, D. G. (1980). Significance tests and goodness of fit in the analysis of covariance structures. Psychological Bulletin, 88(3), 588-606. https://doi.org/10.1037/0033-2909. 88.3.588

Bryan, H. (1977). Leisure value systems and recreational specialization: The case of trout fishermen. Journal of Leisure Research, 9(3), 174-187. https://doi.org/10.1080/00222216.1977.11970328

DiStefano, C., Zhu, M., \& Mîndrilā, D. (2009). Understanding and using factor scores: Considerations for the applied researcher. Practical Assessment, Research \& Evaluation, 14(20), 1-11. https://doi. org/10.7275/da8t-4g52

Havitz, M. E., \& Dimanche, F. (1997). Leisure involvement revisited: Conceptual conundrums and measurement advances. Journal of Leisure Research, 29(3), 245-278. https://doi.org/10.1080/ 00222216.1997.11949796

Hu, L., \& Bentler, P. M. (1999). Cutoff criteria for fit indexes in covariance structure analysis: Conventional criteria versus new alternatives. Structural Equation Modeling, 6(1), 1-55. https:// doi.org/10.1080/10705519909540118

Hvenegaard, G. (2002). Birder specialization differences in conservation involvement, demographics, and motivations. Human Dimensions of Wildlife, 7(1), 21-36. https://doi.org/10.1080/ 108712002753574765

Jun, J., Kyle, G., Graefe, G., \& Manning, R. (2015). An identity-based conceptualization of recreation specialization. Journal of Leisure Research, 47(4), 425-443. https://doi.org/10.1080/00222216.2015. 11950369

Jun, J., Kyle, G., Vlachopoulos, S., Theodorakis, N., Absher, J., \& Hammitt, W. (2012). Reassessing the structure of enduring leisure involvement. Leisure Sciences, 34(1), 1-18. https://doi.org/10.1080/ 01490400.2012 .633847

Kline, R. B. (2011). Principles and practice of structural equation modeling (3rd ed.). The Guilford Press.

Kyle, G., Absher, J., Norman, W., Hammitt, W., \& Jodice, J. (2007). A modified involvement scale. Leisure Studies, 26(4), 399-427. https://doi.org/10.1080/02614360600896668

Lee, J. H., \& Scott, D. (2004). Measuring birding specialization: A confirmatory factor analysis. Leisure Sciences, 26(3), 245-260. https://doi.org/10.1080/01490400490461387

Lessard, S. K., Morse, W. C., Lepczyk, C. A., \& Seekamp, E. (2017). Perceptions of Whooping Cranes among waterfowl hunters in Alabama: Using specialization, awareness, knowledge, and attitudes to understand conservation behavior. Human Dimensions of Wildlife, 23(3), 227-241. https://doi.org/ 10.1080/10871209.2017.1414335 
McFarlane, B. (1994). Specialization and motivations of birdwatchers. Wildlife Society Bulletin, 22(3), 361-370. https://www.jstor.org/stable/3783377

McFarlane, B. (2004). Recreation specialization and site choice among vehicle-based campers. Leisure Sciences, 26(3), 309-322. https://doi.org/10.1080/01490400490461981

McIntyre, N., \& Pigram, J. J. (1992). Recreation specialization reexamined: The case of vehicle-based campers. Leisure Sciences, 14(1), 3-15. https://doi.org/10.1080/01490409209513153

Needham, M., Sprouse, L., \& Grimm, K. (2009). Testing a self-classification measure of recreation specialization among anglers. Human Dimensions of Wildlife, 14(6), 448-455. https://doi.org/10. $1080 / 10871200903032580$

Oh, C., \& Ditton, R. (2006). Using recreation specialization to understand multi-attribute management preferences. Leisure Sciences, 28(4), 369-384. https://doi.org/10.1080/01490400600745886

Oh, C., Sutton, S. G., \& Sorice, M. G. (2013). Assessing the role of recreation specialization in fishing site substitution. Leisure Sciences, 35(3), 256-272. https://doi.org/10.1080/01490400.2013. 780534

Salz, R., \& Loomis, D. (2005). Recreation specialization and anglers' attitudes towards restricted fishing areas. Human Dimensions of Wildlife, 10(3), 187-199. https://doi.org/10.1080/ 10871200591003436

Salz, R. J., Loomis, D. K., \& Finn, K. L. (2001). Development and validation of a specialization index and testing of specialization theory. Human Dimensions of Wildlife, 6(4), 239-258. https://doi.org/ 10.1080/108712001753473939

Schroeder, S. A., Fulton, D. C., Lawrence, J. S., \& Cordts, S. D. (2013). Identity and specialization as a waterfowl hunter. Leisure Sciences, 35(3), 218-234. https://doi.org/10.1080/01490400.2013. 780511

Scott, D., Ditton, R. B., Stoll, J. R., \& Eubanks, T. L., Jr. (2005). Measuring specialization among birders: Utility of a self-classification measure. Human Dimensions of Wildlife, 10(1), 53-74. https://doi.org/10.1080/10871200590904888

Scott, D., \& Shafer, C. (2001). Recreational specialization: A critical look at the construct. Journal of Leisure Research, 33(3), 319-345. https://doi.org/10.1080/00222216.2001.11949944

Shipley, N. J., Larson, L. R., Cooper, C. B., Dale, K., LeBaron, G., \& Takekawa, J. (2018). Do birdwatchers buy the duck stamp? Human Dimensions of Wildlife, 24(1), 61-70. https://doi.org/ 10.1080/10871209.2018.1517227

Sullivan, B. L., Phillips, T., Dayer, A. A., Wood, C. L., Farnsworth, A., Iliff, M. J., Davies, I. J., Wiggins, A., Fink, D., Hochachka, W. M., Rodewald, A. D., Rosenberg, K. V., Bonney, R., \& Kelling, S. (2017). Using open access observational data for conservation action: A case study for birds. Biological Conservation, 208, 5-14. https://doi.org/10.1016/j.biocon.2016.04.031

Sullivan, B. L., Wood, C. L., Iliff, M. J., Bonney, R. E., Fink, D., \& Kelling, S. (2009). eBird: A citizen-based bird observation network in the biological sciences. Biological Conservation, 142(10), 2282-2292. https://doi.org/10.1016/j.biocon.2009.05.006

Sun, J. (2005). Assessing goodness of fit in confirmatory factor analysis. Measurement and Evaluation in Counseling and Development, 37(4), 240-256. https://doi.org/10.1080/07481756.2005.11909764

Wright, D. B., London, K., \& Field, A. P. (2011). Using bootstrap estimation and the plug-in principle for clinical psychology data. Journal of Experimental Psychopathology, 2(2), 252-270. https://doi. org/10.5127/jep.013611 